\title{
Avaliação do serviço de distribuição ao varejo: um estudo empírico no segmento dos médios supermercados
}

\author{
Domingos Fernandes Campos \\ Doutor em Engenharia da Produção pela \\ Universidad Politecnica de Madrid \\ Professor do Mestrado Profissional em \\ Administração da Universidade Potiguar \\ domingos_campos@uol.com.br
}

\author{
ISSNe 2178-9258 \\ ISSN 1678-2089 \\ Organização: Comitê Científico Interinstitucional \\ Editor Científico: José Carlos Lázaro \\ Avaliação: Double Blind Review pelo SEER/OJS \\ Revisão: Gramatical, normativa e de formatação \\ Recebido em 03-08-2011 \\ Aprovação Final em 10-12-2012
}

\section{RESUMO:}

Este artigo tem como objetivo analisar o posicionamento estratégico de distribuidores e atacadistas do varejo alimentar no serviço prestado aos médios supermercados numa cidade do Nordeste brasileiro. Foi realizado um estudo tipo survey com respostas válidas de quarenta médios supermercados. Os resultados da pesquisa permitiram elaborar um ranking da importância dos principais atributos relacionados ao serviço de distribuição, avaliar o nível de satisfação dos varejistas em relação aos seus dez principais distribuidores e analisar como estes últimos se posicionam estrategicamente no mercado em relação a um grupo de atributos do serviço oferecido. Na avaliação do posicionamento estratégico, foram utilizadas matrizes absolutas e relativas de importância e desempenho. Os resultados oferecem uma importante base de conhecimentos para que os gestores do marketing e da logística possam construir matrizes de oportunidades, de forma a reduzir as lacunas do serviço existentes entre as práticas correntes e as melhores práticas do mercado.

Palavras-chave: Cadeia de suprimentos. Logística. Distribuição. Serviço ao cliente. Supermercados.

\section{ABSTRACT:}

This article aims to analyze the strategic positioning of distributors and wholesalers in the retail food industry on the services offered to mid-size supermarkets in a city of the northeast region of Brazil. A survey was conducted within forty mid-size supermarkets. The results of this research made it possible to rank the importance of the main attributes related to distribution services. Moreover, it was possible to analyze the level of satisfaction among retailers in relationship to the top ten distributors and assess how the distributors are positioning themselves strategically in the market, regarding a group of offered service attributes. Matrices of absolute and relative importance and performance were used to assess the strategic positioning of the distributors. The results are important for managers — both marketing and logistic — develop their opportunity matrices, seeking to reduce the existing gaps between their current practices and the benchmark established by the best practices.

Keywords: Supply chain management. Logistics. Distribution. Customer service. Mid-size supermarkets. 
Avaliação do serviço de distribuição ao varejo: um estudo empírico no segmento dos médios supermercados

\section{INTRODUÇÃO}

As organizações precisam desenvolver competências para enfrentar os crescentes desafios do mercado, assumindo um posicionamento diferenciado em relação aos seus concorrentes. O desenvolvimento das competências logísticas deve estar sintonizado com as necessidades dos clientes e as condições objetivas internas da empresa. A logística é um fator essencial que precisa estar alinhado à estratégia das organizações e o seu desempenho está umbilicalmente ligado ao marketing. O esforço para satisfazer as necessidades dos clientes envolve atributos tanto da logística quanto do marketing. Na concepção tradicional do marketing ( $4 \boldsymbol{P} \mathrm{s})$, a praça é, por excelência, o ponto de encontro do marketing e da logística. Nela, a logística dos fornecedores faz desaguar os esforços necessários para alcançar um nível de serviço adequado às necessidades dos clientes, compatível com suas possibilidades internas. As transações ali realizadas conformam o processo de agregação de valor pelo serviço prestado ao cliente.

As empresas fornecedoras devem fundamentar sua estratégia sobre uma base consistente de conhecimentos que revele os elementos essenciais do serviço desejado e as percepções que os clientes têm de diversos atributos associados à distribuição na cadeia de suprimentos. Avaliar as necessidades dos clientes e auditar o serviço externo é uma competência essencial para a construção de uma vantagem competitiva e o sucesso de uma organização. Esse processo não é fácil de ser operacionalizado e envolve algumas questões relacionadas à avaliação do serviço prestado ao cliente. Quais são os indicadores essenciais para o serviço? Qual a importância que os clientes atribuem a cada indicador? Qual a percepção sobre o serviço correntemente prestado? Quais são as melhores práticas reconhecidas por eles? Como os diversos fornecedores se posicionam no mercado em relação ao serviço oferecido? O objetivo deste trabalho é, pois, avaliar o posicionamento das empresas distribuidoras na percepção dos clientes médios supermercadistas.

A pesquisa que lastreia o presente trabalho, além de identificar e analisar a importância que os médios supermercadistas atribuem aos principais atributos do serviço de distribuição e deles obter uma avaliação do serviço prestado por importantes fornecedores, permite desenvolver uma análise das diversas dimensões do serviço oferecido com base no desempenho de cada fornecedor. Os resultados provêm de uma pesquisa exploratória acerca da distribuição aos médios supermercados da cidade de Natal, Brasil. O estudo tipo survey obteve respostas válidas de 40 supermercados atuantes numa área urbana de 800 mil habitantes. Foram identificados e avaliados os dez mais importantes fornecedores, distribuidores e atacadistas, com atuação na distribuição aos médios supermercados da região.

\section{FUNDAMENTAÇÃO TEÓRICA}

A gestão da cadeia de suprimentos é definida como uma coordenação sistêmica e estratégica de funções tradicionais do negócio e das táticas que permeiam cada empresa particular e os negócios interempresariais, com a finalidade de aperfeiçoar o desempenho em longo prazo das empresas envolvidas e da cadeia de suprimentos como um todo. Para Mentzer et al. (2001), a gestão da cadeia de suprimentos se preocupa em melhorar a eficiência com a redução de custos e a eficácia com o serviço ao cliente, criando valor e satisfação para o cliente e obtendo vantagem competitiva e lucratividade. $\mathrm{O}$ ambiente competitivo coloca uma ênfase cada vez maior no nível de serviço aos clientes e torna-se crucial sintonizar a oferta do serviço com as expectativas do cliente.

Bowersox e Closs (2001) utilizam o termo competência logística como um recurso estratégico essencial para o planejamento da prestação do serviço ao cliente. Afirmam que as empresas que desenvolvem competência logística superior estão estrategicamente colocadas para desfrutar uma vantagem competitiva difícil de ser igualada em desempenho de serviço e custo. Para Innis e La Londe (1994), a satisfação do cliente é um dos objetivoschave da função do marketing na maioria das empresas, e a coordenação interfuncional deve ser incentivada para permitir que o marketing e a logística trabalhem juntos, de modo a fornecer uma combinação ótima do serviço ao cliente final. Stock e Lambert (2001) definem serviço como um processo que toma lugar entre cliente, 
fornecedor e terceiros e resulta numa agregação de valor à operação, trazendo, a um custo adequado, benefícios para toda a cadeia.

A percepção do cliente em relação às atividades de prestação de serviços, que é mais visível no momento da distribuição física, deve considerar atributos vinculados à disponibilidade, desempenho e confiabilidade (BOWERSOX; CLOSS, 2001). Se a percepção do cliente em relação a esses três fatores atingir níveis de excelência, existe a possibilidade de a empresa criar uma vantagem competitiva sustentável. É difícil estabelecer uma clara fronteira entre os efeitos provocados na satisfação ao cliente pelos atributos do marketing e da logística. Em certos casos, sequer é possível distinguir com toda clareza se o atributo é eminentemente associado ao serviço do marketing ou da logística. Por outro lado, o que os gestores pensam ser realmente bom para o cliente não se coaduna necessariamente com aquilo que é desejado pelos mesmos. Clientes e fornecedores podem divergir na forma e no conteúdo. O trabalho de Marr (1994) revela uma avaliação interessante entre pontos de vista dos gestores e dos clientes sobre um conjunto de atributos do marketing e da logística, mostrando, ademais, que essas divergências podem se estender entre os próprios gestores dependendo de sua área funcional.

Para Baki et al. (2009), com o crescente progresso das tecnologias de informação (TI) e dos meios de transporte no mundo globalizado, pessoas e empresas vivenciam uma rápida troca de informações e uma fácil circulação de mercadorias, seja no próprio país seja com o exterior. Esse fenômeno tem chamado a atenção para os serviços logísticos. A redução de custos e a manutenção da competitividade necessitam de novas abordagens logísticas com o objetivo de satisfazer os clientes e permanecer competitivo nos negócios. Os autores apontam o fortalecimento da TI como o principal requisito técnico para um serviço de boa qualidade. Por outro lado, Saura et al. (2008), em um estudo realizado com empresas industriais espanholas, mostram que respostas no momento adequado, pessoal, informação e acuracidade dos pedidos são as dimensões mais importantes para a qualidade dos serviços logísticos, tendo uma clara influência, positiva e significativa, sobre a satisfação e a lealdade das empresas clientes. Além disso, os resultados sugerem que a intensidade da TI logística na relação fornecedor-cliente, modula o efeito das demais variáveis. Em situações de alta intensidade da TI, os fatores efeito das previsões, pessoal, informação e qualidade dos pedidos na satisfação e lealdade do cliente são intensificados.

Juga et al. (2010), ao abordarem a questão da utilização de provedores logísticos terceirizados (3PL), reafirmam o papel central da qualidade do serviço percebido na satisfação e na lealdade dos clientes. Concluem que a qualidade do serviço logístico é de fato um fator primordial para a satisfação e a fidelização dos clientes. Para Bourlakis e Melewar (2011), há várias dimensões para as expectativas de desempenho e muitas delas são intangíveis e podem variar significativamente de acordo com o parceiro de negócio. Muitas vezes, as empresas podem ter expectativas indevidas sobre o desempenho de um 3PL por diversas razões (declarações exageradas feitas durante a promoção, gestores que não podem ser plenamente informados). No entanto, outras dimensões são tangíveis e podem ser objetivamente avaliadas. A insatisfação do cliente pode surgir devido ao mau desempenho e/ou à qualidade do serviço prestado pelo 3PL, em comparação com os critérios usados na seleção do 3PL (expectativas). Em ambos os casos, resulta em um impacto negativo sobre o desempenho global do negócio. Banomyong e Supatn (2011) examinaram a qualidade do serviço logístico de entrega por empresas 3PLs. Os resultados indicaram que confiabilidade, garantia e dimensão do custo do serviço foram significativamente relacionadas aos transportadores na seleção de 3PLs. A acuracidade dos documentos foi o atributo com relação mais forte com a seleção de 3PLs, seguido pela oferta de taxas de frete atualizadas e pelo bom atendimento aos clientes.

Os estudos de Kersten e Koch (2010) mostram que os provedores logísticos terceirizados que enfatizam a qualidade do serviço têm maior probabilidade de ser bem-sucedidos do que os concorrentes com uma preocupação exclusiva nos custos. Em um segmento dominado pela intensa concorrência de preços, iniciativas focadas na qualidade podem ser a solução para empresas 
Avaliação do serviço de distribuição ao varejo: um estudo empírico no segmento dos médios supermercados

que não queiram ou não possam reduzir os seus custos Os autores avaliaram a qualidade dos serviços em três dimensões: (a) resultados (condições dos bens entregues, prazos curtos e itens corretos na quantidade pedida); (b) processo (confiabilidade no preenchimento do pedido, rápida resposta às consultas e reclamações, avisos de atrasos); (c) serviço potencial (confiança e cuidado dos empregados, modalidade de pedidos e pedidos especiais, infraestrutura, normas de conformidade e segurança, interface com o sistema ERP do cliente). A análise sugere que a gestão da qualidade afeta positivamente as três dimensões, com maior ênfase no processo.

Mentzer, Gomes e Krapfel (1989) apontaram a existência de dois elementos no serviço de entrega: o serviço do marketing ao cliente e o serviço realizado através da distribuição física. Eles reconhecem a natureza complementar dos dois elementos para satisfazer ao cliente e propõem uma estrutura integrativa do serviço prestado. Gestores de diferentes áreas funcionais de um mesmo fornecedor têm uma visão diferente das necessidades do serviço necessário para seus clientes. Clientes de distintos segmentos têm diferentes apreciações do nível de serviço prestado por um mesmo fornecedor. O nível de serviço planejado por um fornecedor não é aquele que consegue ser oferecido ao seu cliente. $\mathrm{O}$ que o fornecedor pensa que o cliente espera, pode não ser o realmente desejado.

O nível de satisfação do cliente é resultado da oferta de atributos de marketing e de logística, mas o conhecimento deles e o grau de influência de cada um não são, normalmente, claros ou conhecidos. Hijjar (2001) discute a necessidade da busca de indicadores externos e aponta dois motivos importantes para se obter informações com base na perspectiva do cliente: a identificação dos reais níveis de satisfação dos clientes e a minimização dos gaps de percepção entre a empresa e o cliente. Mentzer, Flint e Hult (2001) assinalam que os pesquisadores fornecem frequentemente uma lista de dimensões dos serviços da logística para as quais os clientes dão forma às suas percepções. Essas operacionalizações ignoram os processos, isto é, o ordenamento temporal dos atributos que estão sendo testados. Alguns atributos não só são correlacionados, mas dependentes de outros. Constatam, ademais, que esses processos variam para negócios de diferentes segmentos.

\subsection{O Serviço no Varejo}

No varejo, a oferta de níveis de serviço adequados assume um papel chave para o mercado. Ellram, La Londe e Weber (1999) apontaram três grandes desafios para a logística do varejo: (a) os varejistas devem viabilizar e implantar a ideia de que o serviço ao cliente deveria se expandir para toda a cadeia de suprimentos; (b) os gestores da logística do varejo deveriam estar preparados para os efeitos do rápido crescimento da tecnologia, particularmente 0 crescimento explosivo da tecnologia de informação; (c) a gestão da cadeia de suprimentos deveria ser desenvolvida e integrada para explorar estratégias de aperfeiçoamento do serviço ao cliente e do gerenciamento dos estoques.

No entendimento de Christopher (1997), no contexto do serviço ao cliente, é primordial o entendimento dos fatores que mais influenciam o comportamento do comprador. Uma falha comum do marketing é deixar de compreender que nem sempre os clientes atribuem a mesma importância às diversas características do produto ou do serviço. O autor propõe um processo de três estágios para a segmentação dos clientes em relação ao serviço: (a) identificar os componentes-chave do serviço; (b) estabelecer a importância relativa dos atributos; (c) identificar os grupos de clientes com preferências similares.

Por outro lado, Stock e Lambert (2001) propõem um procedimento de auditoria para avaliar o nível de serviço de uma empresa e servir como benchmark para estimar o impacto de mudanças na política de serviço ao cliente. $\mathrm{O}$ procedimento contempla quatro estágios: (a) uma auditoria externa do serviço para identificar os atributos que os clientes julgam mais importante para a compra e como eles percebem o serviço oferecido; (b) uma auditoria interna com o propósito de identificar inconsistências entre as práticas da empresa e as expectativas dos clientes; (c) a identificação de soluções potenciais que permitam o ajuste da estratégia e aumente a lucratividade; (d) o estabelecimento de padrões para acompanhar o desempenho na oferta do serviço aos clientes. 
Quando apurados corretamente, os indicadores externos podem oferecer uma base confiável para o processo de avaliação do serviço ao cliente. Uma série de inconsistências tende a emergir quando são comparados os resultados de auditorias externa e interna, revelando desajustes no foco das estratégias do serviço. Recursos podem estar sendo alocados inadequadamente em atributos pouco valorizados, em detrimento de outros muito importantes para os clientes. A prática empresarial pode estar inconsistente com as ideias originais que os gestores tentam imprimir. Parasuraman, Zeithaml e Berry (1990) apresentam um modelo de qualidade de serviço focado nas lacunas (gaps) existentes entre diferentes práticas e percepções dos fornecedores e de seus clientes. Afirmam que essas lacunas contribuem para o empobrecimento da qualidade do serviço percebido pelos clientes.

Grönroos (2006) afirma que é razoável admitir que a qualidade percebida de um serviço seja o resultado de um processo de avaliação em que o consumidor (cliente) compara suas expectativas com o serviço que efetivamente percebeu receber, contrapondo serviço percebido e serviço esperado; o resultado desse processo seria a qualidade de serviço percebida. Bowersox, Closs e Cooper (2006) compartilham o pensamento de Grönroos e afirmam que é realístico pensar que uma empresa, ao satisfazer as expectativas de clientes de maneira mais adequada que seus competidores, irá ganhar alguma vantagem competitiva no mercado; não obstante, chamam a atenção para o fato de que satisfação não é o mesmo que felicidade. Um cliente poderia ficar satisfeito ao receber um nível de serviço baixo, se suas expectativas em relação ao mesmo fossem muito baixas. Ou, ainda, poderia ficar insatisfeito, se suas expectativas fossem elevadas. A Figura 1 ilustra a combinação de desempenho e expectativas apresentada pelos autores.

Figura 1 - Matriz expectativa $\mathrm{x}$ desempenho

\begin{tabular}{|c|c|c|c|c|}
\hline & \multicolumn{3}{|c|}{ Expectativa } \\
\hline & & baixa & média & alta \\
\hline \multirow{3}{*}{$\begin{array}{l}0 \\
\frac{1}{\delta} \\
0 \\
0 \\
0 \\
0 \\
0 \\
0 \\
0\end{array}$} & alto & muito satisfeito & muito satisfeito & satisfeito \\
\hline & médio & muito satisfeito & satisfeito & insatisfeito \\
\hline & baixo & satisfeito & insatisfeito & insatisfeito \\
\hline
\end{tabular}

Fonte: Bowersox et al. (2006).
É desejável que os atributos utilizados tenham importância para os clientes e estejam sintonizados com a política de serviço. Em relação à utilização de atributos e dimensões do nível de serviço, Griffis et al. (2004) alertam para a falta de conexão entre a necessidade de medir e a escolha das medidas adequadas. Para os autores, existem três situações que podem afetar significativamente o desempenho: a) quando nenhuma medida é escolhida para avaliar o desempenho; b) quando as medidas utilizadas são não confiáveis, inconsistentes, ou inválidas; c) quando as medidas são escolhidas sem a consideração das reais necessidades da empresa. A literatura tem oferecido um leque variado de dimensões e atributos do nível de serviço logístico e do nível de serviço do marketing. Os trabalhos de La Londe e Zinszer (1976), La Londe, Cooper e Noordewier (1988), Mentzer, Gomes e Krapfel (1989), Innis e La Londe (1994), Griffis et al (2004) e Kersten e Koch (2010) apresentam um conjunto extenso dessas dimensões.

No Brasil, vários trabalhos têm sido desenvolvidos na área do varejo alimentar como os de Fleury e Lavalle (1997), Hijjar (2001), Lavalle et al. (2003). Lavalle (2007), em pesquisa sobre as relações da indústria com as grandes cadeias de supermercados, realizada anualmente desde 1994 (LAVALLE, 2007), mostra que o serviço de distribuição tem alcançado, em relação aos outros Ps do marketing, uma importância de $20 \%$ na decisão de compra dos supermercadistas.

$\mathrm{Na}$ área do pequeno varejo alimentar, os trabalhos de Campos (2007, 1), Campos (2007, 2) mostram diversos aspectos do serviço de distribuição prestado por distribuidores e atacadistas aos varejistas do setor. Os principais atributos do serviço foram identificados pelo grau de importância e comparados às percepções de clientes e gestores. Os atributos regularidade do prazo de entrega, qualidade do atendimento dos vendedores, entrega completa e tamanho do prazo de entrega receberam, na sequência, graus de importância mais elevados. $\mathrm{Na}$ área dos supermercados médios pode-se apontar o trabalho de Maia (2006). O autor avalia o serviço logístico sob a percepção de médios supermercadistas, verificando quais são os atributos mais valorizados e quais desses fatores determinam a manutenção das parcerias e 
Avaliação do serviço de distribuição ao varejo: um estudo empírico no segmento dos médios supermercados

alianças com fornecedores na cadeia de abastecimento.

\section{METODOLOGIA}

Os resultados aqui apresentados provêm de um estudo do tipo survey realizado com supermercados de porte médio na cidade do Natal, Rio Grande do Norte. O estudo tem natureza exploratória e o interesse principal é o conhecimento dos atributos do serviço da distribuição que contribuem mais significativamente para o nível de satisfação dos médios supermercadistas da região. A pesquisa converge para o que Stock e Lambert (2001) chamam de auditoria externa do serviço ao cliente, cujos objetivos são identificar os elementos do serviço que os clientes acreditam ser importantes quando tomam a decisão de comprar, e determinar como os clientes percebem o serviço oferecido por cada um dos seus fornecedores.

Figura 2 - Fluxo de materiais na cadeia de suprimentos

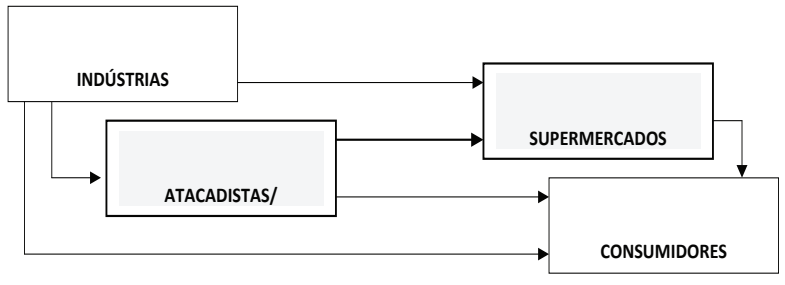

elo avaliado em destaque

Fonte: Elaboração própria.

$\mathrm{Na}$ cadeia de suprimentos do varejo, os fluxos de bens e serviços mais importantes que alcançam os supermercados são provenientes da indústria. Chegam até eles diretamente da indústria ou são mediados pela ação de atacadistas e distribuidores. Esses fluxos são mostrados na Figura 2. O relacionamento atacadistas/ distribuidores e supermercados médios representa o elo que é objeto da pesquisa realizada.

A população-alvo é constituída pelos médios supermercadistas. Não há consenso sobre a denominação e os limites precisos para o tamanho dos supermercados. Nesta pesquisa, foram consideradas as lojas na faixa de 4 a 10 checkouts (caixas), que é a classificação utilizada correntemente pelos distribuidores locais para os supermercados médios. Esse mesmo domínio foi observado no estudo de Flud (2006). Os supermercados médios representam uma importante parcela do segmento no Brasil. A Tabela 1 mostra a participação das empresas do varejo no segmento alimentar brasileiro, de acordo com o Censo 2007 da Nielsen Consultoria. Os resultados são apresentados pela Revista Supermercado Moderno (2008).

Tabela 1 - Perfil de vendas nos supermercados

VENDAS NOS SUPERMERCADOS DO BRASIL POR TAMANHO DE LOJA

\begin{tabular}{|c|c|c|}
\hline $\mathrm{N}^{0}$ de Caixas & $\mathrm{N}^{0}$ de Lojas & \% Vendas \\
\hline 10 ou mais & 2.615 & 59,5 \\
\hline 5 a 9 & 3.950 & 14,4 \\
\hline até 4 & 58.955 & 26,1 \\
\hline total & 65.520 & 100 \\
\hline
\end{tabular}

Fonte: Revista Supermercado Moderno (2008).

O processo de escolha dos atributos foi realizado em duas fases e direcionado para incluir variáveis consideradas como as mais importantes na literatura. Num primeiro momento, tomaram-se como base os atributos utilizados na pesquisa de Campos $(2007,1)$. Nessa pesquisa, o serviço de distribuição é auditado no relacionamento atacadistas/distribuidores e pequenos varejistas do segmento alimentar, canal similar ao do presente estudo. Os atributos são de natureza logística ou associados à atividade de comercialização. Procurou-se, ademais, incluir atributos que por hipótese interessavam aos clientes, mas eram vinculados ao nível de serviço do marketing, como prazo e forma de pagamento e limite de crédito. Para efeitos de comparação, incluiu-se a variável preço na lista de atributos a serem avaliados.

Num segundo momento, buscou-se uma empresa com distribuição no segmento dos médios supermercados, com o objetivo de discutir e analisar as variáveis que compunham o questionário $\mathrm{e}$, ao mesmo tempo, que cedesse uma lista completa dos supermercados médios da região em estudo. Houve o compromisso ético de se manter sigilo sobre a identidade da empresa e de se utilizar as informações com a finalidade única de realização da pesquisa. Um grupo focal foi montado com a participação dos diretores da empresa, do gerente comercial, do gerente de logística e de três coordenadores de área, além do autor, que foi responsável pela coordenação das sessões. O procedimento de ausculta é necessário, na medida em que contribui para assegurar que as varáveis utilizadas são importantes e pertinentes na avaliação do nível de serviço prestado pelos distribuidores. $\mathrm{O}$ processo assemelha-se ao 
aplicado por Marr (1994), Mentzer, Flint e Hult (2001) e

Stank, Daugherty e Ellinger (1997). A Tabela 2 apresenta

a lista de atributos utilizados na pesquisa.

Tabela 2 - Lista de atributos utilizados

\begin{tabular}{|c|c|}
\hline Definição & Natureza \\
\hline 1. Frequência de passagem do vendedor no cliente num dia certo. & $\mathrm{M} / \mathrm{L}$ \\
\hline $\begin{array}{l}\text { 2. Qualidade no atendimento (cordialidade, clareza e presteza nas informações, } \\
\text { conhecimento técnico dos produtos) oferecida pelo vendedor. }\end{array}$ & $\mathrm{M} / \mathrm{L}$ \\
\hline 3. Prazo de entrega da mercadoria prometido pelo fornecedor após o fechamento do pedido. & $\mathrm{L}$ \\
\hline $\begin{array}{l}\text { 4. Regularidade do prazo de entrega, isto é, receber sempre no dia prometido pelo } \\
\text { fornecedor. }\end{array}$ & $\mathrm{L}$ \\
\hline $\begin{array}{l}\text { 5. Serviço de entrega (informação, atenção, cordialidade, agilidade, presteza) realizado } \\
\text { pelos funcionários do fornecedor. }\end{array}$ & $\mathrm{L}$ \\
\hline $\begin{array}{l}\text { 6. Serviço de assistência pós-venda (tratamento de avarias, trocas, devoluções, } \\
\text { reclamações) prestado pelo fornecedor. }\end{array}$ & $\mathrm{L}$ \\
\hline $\begin{array}{l}\text { 7. Entrega vinda completa do fornecedor, com todos os itens, sem erros de quantidade, sem } \\
\text { produtos trocados, mercadoria vencida ou avariada. }\end{array}$ & $\mathrm{L}$ \\
\hline $\begin{array}{l}\text { 8. Precisão e confiabilidade dos dados das notas fiscais emitidas pelos fornecedores, sem } \\
\text { erros de identificação, códigos, quantidades e alíquotas. }\end{array}$ & $\mathrm{L}$ \\
\hline 9. Prazo de pagamento oferecido para suas compras pelos seus fornecedores. & M \\
\hline $\begin{array}{l}\text { 10. Forma de pagamento oferecida para as compras do cliente (em dinheiro, cheque, boleto } \\
\text { bancário, ...) pelo fornecedor. }\end{array}$ & M \\
\hline 11. Preços praticados e negociados com o fornecedor nas compras. & M \\
\hline $\begin{array}{l}\text { 12. Trabalho de merchandising (arrumação, limpeza, reposição de prateleiras, mostradores, } \\
\text { gôndolas, material promocional e outras orientações) realizado em seu negócio por } \\
\text { promotores do fornecedor. }\end{array}$ & M \\
\hline $\begin{array}{l}\text { 13. Acesso fácil e direto aos funcionários do fornecedor (supervisores e gerente } \\
\text { comercial, pessoal da área de entregas, da área financeira, diretores). }\end{array}$ & $\mathrm{M} / \mathrm{L}$ \\
\hline $\begin{array}{l}\text { 14. Flexibilidade do fornecedor em oferecer diferentes possibilidades de negociação de } \\
\text { preços e prazos em encartes, aniversários e campanhas promocionais. }\end{array}$ & M \\
\hline $\begin{array}{l}\text { 15. Pedidos extras, fora dos dias de visita, de diferentes produtos e quantidades, garantindo } \\
\text { o fornecimento quando demandado. }\end{array}$ & $\mathrm{M} / \mathrm{L}$ \\
\hline 16. Limite de crédito, valor máximo para compra a prazo, oferecido pelo fornecedor. & M \\
\hline
\end{tabular}

Fonte: Elaboração própria.

Foram identificados 59 varejistas classificados como médios supermercados na área de estudo. Em algumas situações, havia mais de uma loja por empresa, situação na qual havia um mesmo responsável pelas compras para mais de uma loja. Dessa forma, o número de contatos para a aplicação do questionário foi reduzido para 45 empresas. O questionário da pesquisa foi estruturado em três módulos. O primeiro contemplava um conjunto de 16 questões para as quais se arguia a importância que o supermercadista conferia a cada atributo, em função do seu negócio. A avaliação da importância do atributo foi realizada usando-se uma escala, com números inteiros variando de zero (não importante) a dez (muito importante). Nesse módulo, o respondente atribuía uma nota de zero a dez, de forma independente, a cada atributo apresentado na Tabela 2, segundo a percepção da importância que o item teria para a sua decisão de compra aos fornecedores.

O segundo módulo demandava como resposta dos clientes supermercadistas a hierarquização dos mesmos 16 atributos tomados na primeira série de questões. Aqui, cada respondente, de forma comparativa, pelo grau de importância, era orientado a hierarquizar previamente os dezesseis atributos e a eles atribuir, gradativamente, sem repetição, uma nota de um a dezesseis, sendo dezesseis (16) para o item mais importante e um (1) para o item menos importante. Nesse módulo, o respondente foi compelido a fazer uma reflexão sobre a importância que um atributo teria em relação aos demais.

No terceiro módulo, os supermercadistas foram instados a avaliar o desempenho de seus fornecedores em relação à mesma lista de atributos apresentada na Tabela 2. As dez maiores empresas distribuidoras foram identificadas através da relação dos cem maiores contribuintes do imposto sobre circulação de mercadorias (ICMS) no Estado do Rio Grande do Norte em 2004. Sete deles estão na lista do ranking da ABAD (2005) dos 100 
Avaliação do serviço de distribuição ao varejo: um estudo empírico no segmento dos médios supermercados

maiores distribuidores do Brasil. Os demais não constam na lista por não ter disponibilizado seus resultados aos editores; no entanto, pelas receitas brutas anuais, fariam parte dessa relação. Constaram empresas com atuação nacional, regional e estadual na área de alimentos, produtos de limpeza e higiene pessoal. A avaliação do desempenho de cada fornecedor foi realizada usando-se uma escala numérica, com números inteiros variando de zero (péssimo) a dez (excelente desempenho). A formatação inicial do questionário foi submetida a um pré-teste envolvendo 5 médios supermercadistas. Os resultados revelaram a necessidade de se promover pequenos ajustes. Foram coletados dados de tamanho sobre quatro bases distintas: faturamento mensal, número de funcionários, número de caixas (checkouts) e área de vendas. A equipe de aplicadores foi orientada a dirigirse, quando possível, diretamente ao responsável pelas compras. O tratamento estatístico foi realizado utilizandose o Statistical Package for the Social Science - SPSS, versão 12.0 .

\section{RESULTADOS}

Os resultados aqui apresentados refletem a apuração de 40 respostas válidas de 45 supermercados médios contatados, representando um taxa de retorno de 88,9\%. Foram utilizadas quatro medidas que refletem o tamanho dos estabelecimentos pesquisados, a saber: o número de funcionários, o número de caixas (checkouts), o faturamento bruto mensal e a área de vendas. A Tabela 3 apresenta a distribuição dos estabelecimentos por número de funcionários e por número de caixas. A Tabela 4 mostra a distribuição de estabelecimentos pela área de vendas e pelo faturamento bruto mensal.

Tabela 3 - Distribuição dos varejistas por funcionários e por número caixas

\begin{tabular}{|l|c|c|l|c|c|}
\hline $\begin{array}{c}\text { Número de } \\
\text { Funcionários }\end{array}$ & Quantidade & $\%$ & $\begin{array}{c}\text { Númer0 } \\
\text { de Caixas }\end{array}$ & Quantidade & $\%$ \\
\hline até 25 & 14 & 35,0 & até 4 & 12 & 30,0 \\
\hline $26-50$ & 15 & 37,5 & $5-6$ & 12 & 30,0 \\
\hline $51-75$ & 8 & 20,0 & $7-8$ & 9 & 22,5 \\
\hline $76-100$ & 0 & 0,0 & $9-10$ & 3 & 7,5 \\
\hline mais de 100 & 3 & 7,5 & mais de 10 & 4 & 10,0 \\
\hline \hline
\end{tabular}

Fonte: Pesquisa.
Tabela 4 - Distribuição dos varejistas por área de vendas e por faturamento

\begin{tabular}{|l|c|c|l|c|c|}
\hline $\begin{array}{l}\text { Área de Vendas } \\
\left(\mathrm{m}^{2}\right)\end{array}$ & Quantidade & $\%$ & $\begin{array}{c}\text { Faturamento } \\
\text { Mensal (RS1.000) }\end{array}$ & Quantidade & $\%$ \\
\hline até 350 & 9 & 22,5 & at'́ 250 & 13 & 32,5 \\
\hline $351 \cdot 700$ & 22 & 55,0 & $251 \cdot 500$ & 17 & 42,5 \\
\hline $701 \cdot 1050$ & 4 & 10,0 & $501-750$ & 3 & 7,5 \\
\hline $1051 \cdot 1400$ & 1 & 2,5 & $751 \cdot 1000$ & 3 & 7,5 \\
\hline mais de 1400 & 4 & 10,0 & mais de 1000 & 4 & 10,0 \\
\hline
\end{tabular}

Fonte: Pesquisa.

Verifica-se que os médios supermercadistas, em sua maioria, empregam até 75 funcionários (92,5\%), operam até 8 caixas $(82,5 \%)$, disponibilizam uma área de vendas de até $1050 \mathrm{~m} 2(87,5 \%)$ e faturam até 750 mil por mês $(82,5 \%)$. A média global de empregados por estabelecimento foi de 43,3 funcionários. O número médio de caixas por varejista foi de 6,9 e a área média de vendas, 636,0 $\mathrm{m} 2$. O faturamento médio mensal informado por loja foi de R\$ 495.250,00.

\subsection{A Percepção da Importância dos Atributos pelos Supermercadistas}

Foram utilizadas duas escalas para avaliar a importância de cada atributo na percepção dos supermercadistas. $\mathrm{Na}$ primeira avaliação, cada respondente foi instado a atribuir uma nota de zero a dez para a importância de cada variável, de forma sequencial e independente, sem ser estimulado a realizar qualquer comparação entre os atributos. As médias nominais obtidas variaram de 8,5250 a 9,8750, situando-se, todas, no quinto superior da escala. Uma análise preliminar permite aferir que os supermercadistas consideram muito importantes todos os atributos que lhes foram apresentados. $\mathrm{O}$ resultado global não surpreende porque os atributos avaliados na pesquisa foram extraídos dentre aqueles já considerados muito importantes na literatura.

As diferenças numéricas entre as médias, face ao número de respondentes e consequente erro estatístico, não oferecem elementos discriminantes significativos para assegurar uma confiabilidade no ordenamento dos atributos, o que torna possível a ocorrência de mudanças no ordenamento (ranking) dos atributos avaliados. Ou seja, os resultados apurados nessa escala são suficientes 
para afirmar que os respondentes consideram todos os atributos muito importantes, mas não o bastante para assegurar uma hierarquização entre eles com alto nível de confiabilidade.

Por outro lado, no segundo módulo do questionário, cada respondente foi instado a hierarquizar, mediante comparação de importância, todos os atributos. Cada respondente escolhia inicialmente $o$ atributo que considerava mais importante e atribuía-lhe a nota máxima de uma escala ordinal que variava de um a dezesseis. Em seguida, buscava dentre os quinze restantes o segundo mais importante e atribuía-lhe a nota 15 (quinze). Prosseguia nas comparações até que restasse o último atributo (menos importante), atribuindo-lhe a nota 1 (um). A Tabela 5 revela o ordenamento da importância dos atributos conferidos pelos supermercadistas. A primeira parte mostra as médias de importância de cada atributo conferidas de forma independente e a segunda, as médias obtidas na hierarquização por comparação.

Tabela 5 - Grau de importância dos atributos

\begin{tabular}{|l|c|c|c|c|}
\hline \multirow{2}{*}{ Atributo } & \multicolumn{2}{|c|}{ Respostas Independentes } & \multicolumn{2}{c|}{ Respostas Comparadas } \\
\cline { 2 - 5 } & Média & Ranking & Média & Ranking \\
\hline Qualidade Atendimento do Vendedor & 9,3750 & 8 & 12,1500 & 1 \\
\hline Assistência Ṕ́s-Venda & 9,6750 & 2 & 12,1250 & 2 \\
\hline Frequência Passagem do Vendedor & 9,5250 & 4 & 11,6750 & 3 \\
\hline Entrega Completa & 9,8750 & 1 & 11,3500 & 4 \\
\hline Regularidade da Entrega & 9,3250 & 9 & 11,2000 & 5 \\
\hline Precisão e Confiabilidade Notas Fiscais & 9,5750 & 3 & 10,9250 & 6 \\
\hline Prazo de Entrega & 9,4750 & 6 & 10,7000 & 7 \\
\hline Serviço de Entrega & 9,0750 & 12 & 7,9000 & 8 \\
\hline Preços Praticados e Negociados & 9,4500 & 7 & 7,5750 & 9 \\
\hline Merchandising & 9,1500 & 11 & 6,8250 & 10 \\
\hline Flexibilidade Preços e Prazos & 9,5250 & 5 & 6,4750 & 11 \\
\hline Prazo de Pagamento & 9,2000 & 10 & 6,4500 & 12 \\
\hline Forma de Pagamento & 9,0000 & 14 & 6,0500 & 13 \\
\hline Acesso Fácil e Direto ao Fornecedor & 8,5250 & 16 & 5,3250 & 14 \\
\hline Pedidos Extras & 8,9750 & 15 & 4,8500 & 15 \\
\hline Limite de Crédito p/Compra a Prazo & 9,0500 & 13 & 4,4250 & 16 \\
\hline
\end{tabular}

Fonte: Pesquisa.

A resposta comparativa, embora seja imprecisa na avaliação do posicionamento dos atributos numa escala absoluta de graus de importância, é eficaz na revelação do posicionamento relativo dos atributos. No grupo mais bem avaliado, constam sete atributos, pela ordem: qualidade de atendimento do vendedor; assistência pós-venda frequência de passagem do vendedor; entrega completa; regularidade do prazo de entrega; precisão e confiabilidade das notas fiscais; tamanho do prazo de entrega. Desses atributos, cinco são vinculados exclusivamente ao serviço logístico. Qualidade do atendimento e frequência de passagem do vendedor são gerenciados tanto pelo marketing quanto pela logística. O preço figura em nono lugar e a flexibilidade do fornecedor em oferecer diferentes possibilidades de preços e prazos em campanhas promocionais em décimo primeiro lugar, dentre os 16 atributos avaliados.

A frequência de passagem do vendedor é aparentemente uma variável gerenciada pelo marketing. No entanto, em termos práticos, ela é determinada pela capacidade da distribuição física em atender a área do cliente mais frequentemente e pelo balanceamento entre o ganho no nível de satisfação do cliente - e consequente aumento nas vendas - e os custos adicionais gerados pelo atendimento mais frequente da rota. O atributo qualidade de atendimento do vendedor reflete uma aplicabilidade imediata dos conhecimentos do marketing, mas está intimamente associado ao serviço logístico por lidar com suas condições pré-transacionais e por estar envolvido diretamente com o ciclo do pedido. Nos dois rankings de respostas, os atributos forma de pagamento, acesso fácil e direto ao fornecedor, pedidos extras e limite de crédito para compras a prazo se situaram nos quatro últimos lugares.

Embora os dois ordenamentos apresentados na Tabela 5 possam, preliminarmente, sugerir que as avaliações da importância dos atributos pelas duas metodologias conduzam a resultados significativamente diferentes, é possível que algumas mudanças de posição no ranking sejam absorvidas pelo erro estatístico. As respostas comparativas, em tese, pelo procedimento de hierarquização utilizado, representam um ordenamento mais confiável. A divergência ou convergência entre as ordenações indica o grau de alinhamento entre os resultados oferecidos por um e outro método. $\mathrm{O}$ alinhamento, então, pode ser verificado pelo grau de correlação existente entre as duas ordenações. Um coeficiente de correlação 1,0 indicaria um grau de alinhamento $100 \%$, um coeficiente $-1,0$ indicaria um (des)alinhamento completo. 
Avaliação do serviço de distribuição ao varejo: um estudo empírico no segmento dos médios supermercados

Tabela 6 - Grau de alinhamento entre as respostas comparadas e independentes

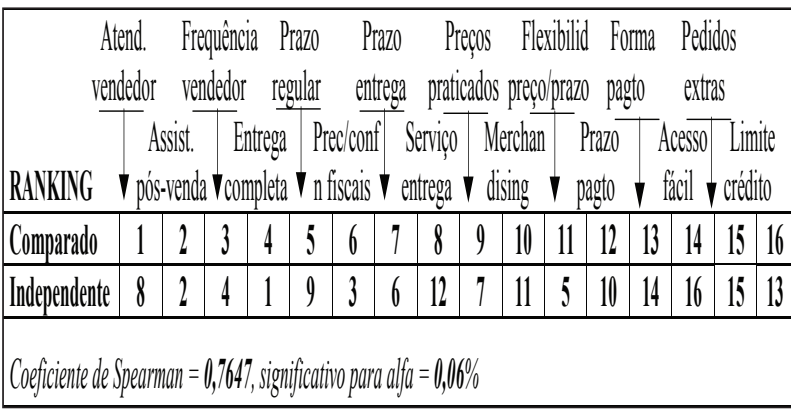

Fonte: Pesquisa.

Cooper e Schindler (2003) apontam os coeficientes de correlação de Spearman e de Kendall como os mais utilizados para comparação de séries de valores ordinais. O teste de correlação de Spearman analisa os resíduos através das diferenças entre as posições hierarquizadas de cada variável. O coeficiente de Spearman seria equivalente ao de Pearson, aplicado às ordenações sem, no entanto, exigir as condições de normalidade da população e a relação linear entre as variáveis. A Tabela 6 mostra a comparação dos dois ordenamentos obtidos. O teste de Spearman revelou um coeficiente de 0,7647, com um nível de significância de $0,06 \%$. O teste aponta, ainda assim, um grau de alinhamento significativo entre as respostas.

\subsection{APercepçãodoServiçopelos Supermercadistas}

Aos supermercadistas foi solicitado que fizessem uma avaliação do serviço de distribuição oferecido pelos dez fornecedores mais importantes do Estado. Os respondentes avaliaram o serviço em relação a cada atributo da Tabela 2. As notas variaram de zero (péssimo desempenho) a dez (excelente desempenho). A Tabela 7 apresenta as médias obtidas pelas distribuidoras em cada um dos dezesseis atributos pesquisados. Os atributos foram ordenados pela importância comparada. As avaliações refletem a percepção do varejista sobre o nível de serviço oferecido e medem, no conjunto de atributos, o nível de desempenho dos seus fornecedores.

De um total máximo de 160 pontos alcançáveis, a avaliação do serviço de distribuição dos fornecedores variou de um mínimo de 87,2 (54,5\%) pontos para a distribuidora $\boldsymbol{A}$, a um máximo de $138,8(86,8 \%)$ pontos obtido pela distribuidora $\boldsymbol{E}$. Isso sugere que a lacuna (gap) entre o serviço prestado pelo fornecedor e aquele idealizado pelos clientes variou de 21,2 pontos a 72,8 pontos. A avaliação global do serviço de distribuição da empresa A representa apenas $62,8 \%$ do desempenho da empresa $\boldsymbol{E}$.

Os clientes perceberam, portanto, um profundo gap entre os serviços oferecidos por elas. O desempenho dos fornecedores em cada atributo pode ser comparado com o máximo de pontos da escala (dez) e com as melhores práticas alcançadas. A lacuna entre o desempenho de cada fornecedor e a pontuação máxima não leva em conta as condições concorrenciais, devendo, portanto, merecer uma atenção mais restrita do que a lacuna em relação às melhores práticas. Os serviços foram percebidos na faixa de um mínimo de 2,20 para merchandising, empresa A, a um máximo de 9,20, qualidade do atendimento dos vendedores, empresa E, sugerindo que a escala de avaliação do desempenho foi adequada.

Tabela 7 - Avaliação dos fornecedores em cada atributo e ranking global

\begin{tabular}{|c|c|c|c|c|c|c|c|c|c|c|c|}
\hline \multirow{2}{*}{ Atributo } & \multirow{2}{*}{$\begin{array}{l}\text { Grall } \\
\text { Imp }\end{array}$} & \multicolumn{10}{|c|}{ Médlias das Avaliaçōes das Empresas Distribuidoras } \\
\hline & & A & B & C & D & E & $\mathrm{F}$ & G & $\mathrm{H}$ & 1 & \\
\hline & 12,15 & 5,98 & 6,03 & 8,55 & 88 & 9,20 & 7,38 & 7,65 & 7,05 & 7,95 & \\
\hline & 12,13 & 3,70 & 4,43 & 6,03 & 88 & 9,13 & 3,93 & 6,75 & 6,60 & 7,05 & \\
\hline & 11,68 & 5,70 & 5,60 & 8,25 & 05 & 9,05 & 7,33 & 7,78 & 7,20 & 8,40 & \\
\hline & 11,35 & 6,50 & 7,20 & 8,15 & 6,95 & 8,45 & 6,38 & 7,55 & 7,33 & 7,43 & \\
\hline e prazo & 11,20 & 3,93 & 6,83 & 7,98 & 6,78 & 9,15 & 6,73 & 7,70 & 7,13 & 6,50 & \\
\hline ConffPr & 10,93 & 7,03 & 7,38 & 8,30 & 7,60 & 8,88 & 7,70 & 7,88 & 7,55 & 7,98 & \\
\hline 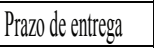 & 10,70 & 4,40 & 6,58 & 8,08 & 6,58 & 9,10 & 6,65 & 7,43 & 7,23 & 6,90 & \\
\hline & 7,90 & 5,90 & 6,40 & 7,78 & 7,05 & 8,23 & 6,90 & 7,05 & 6,95 & & \\
\hline ados & 7,58 & 6,00 & 6,35 & 6,68 & 6,63 & 7,88 & 7,45 & 7,48 & 7,30 & 7,35 & \\
\hline Merchar & 6,83 & 2,20 & 2,40 & 7,50 & 4,85 & 8,48 & 2,80 & 7,53 & 7,33 & 7,48 & \\
\hline Flexibp & 6,48 & 3,98 & 4,78 & 7,38 & 6,60 & 8,78 & 4,90 & 7,68 & 7,73 & 7,75 & \\
\hline Prazo de & 6,45 & 7,10 & 6,93 & 6,68 & 7,00 & 8,60 & 7,45 & 7,75 & 7,25 & 8,15 & \\
\hline Forma de & 6,05 & 7,95 & 7,33 & 8,18 & 7,95 & 8,28 & 7,38 & 8,05 & 7,88 & 7,88 & \\
\hline Acesso f & 5,33 & 4,15 & 4,33 & 6,50 & 5,68 & 8,15 & 5,30 & 6,40 & 6,10 & 6,43 & 6, \\
\hline Pedidose & 4,85 & 4,85 & 5,80 & 7,80 & 6,90 & 8,55 & 6,63 & 7,33 & 7,50 & 7,78 & \\
\hline Limited & 4,43 & 7,80 & 7,48 & 8,63 & 7,30 & 8,90 & 7,75 & 7,80 & 8,15 & 8,45 & \\
\hline EAvaliac & & 87,2 & 95,8 & 122,4 & 106,7 & 138,8 & 102,6 & 119,8 & 116,3 & 120,5 & \\
\hline Ranking empresas & & 10 & 9 & 3 & 7 & 1 & 8 & 5 & 6 & 4 & \\
\hline
\end{tabular}

Fonte: Pesquisa.

O posicionamento de cada fornecedor pode ser revelado em múltiplos cenários. É importante considerar a comparação com as melhores práticas, com a prática média do setor e com as práticas do principal concorrente. 
De acordo com o escopo do trabalho e em função do alto número de combinações possíveis (10 empresas e 16 atributos), por um critério de acessibilidade - facilidade em obter as informações necessárias para a análise -, foi escolhida a empresa $\boldsymbol{F}$ como foco da avaliação. A direção da empresa $\boldsymbol{F}$ elegeu a empresa distribuidora $\boldsymbol{I}$ como sua principal concorrente. Ambas mantêm em suas carteiras produtos alimentares, de limpeza e higiene pessoal. As duas empresas atuam no segmento atacadista com uma gama similar de mercadorias e são distribuidoras exclusivas de produtos, também concorrentes.

Tabela 8 - Resumo dos índices

\begin{tabular}{|c|c|c|c|c|c|c|c|}
\hline Atributo & $\begin{array}{l}\text { Griau de } \\
\text { Importa }\end{array}$ & $\begin{array}{l}\text { Média } \\
\text { Global }\end{array}$ & $\begin{array}{l}\text { Piores } \\
\text { Práticas }\end{array}$ & $\begin{array}{c}\text { Empresa } \\
\text { F }\end{array}$ & $\begin{array}{c}\text { Empresa } \\
\text { I }\end{array}$ & $\begin{array}{l}\text { Melhores } \\
\text { Práticas }\end{array}$ & $\begin{array}{l}\text { Máíimo } \\
\text { Pontos }\end{array}$ \\
\hline Atend. vendedor & 12,15 & 7,44 & 5,98 & 7,38 & 7,95 & 9,20 & 10 \\
\hline Assist. pós-renda & 12,13 & 6,16 & 3,70 & 3,93 & 7,05 & 9,13 & 10 \\
\hline Passag, vendedor & 11,68 & 7,26 & 5,60 & 7,33 & 8,40 & 9,05 & 10 \\
\hline Entregeg completa & 11,35 & 7,43 & 6,38 & 6,38 & 7,43 & 8,45 & 10 \\
\hline Prazo regular" & 11,20 & 7,06 & 3,93 & 6,73 & 6,50 & 9,15 & 10 \\
\hline Confiablipecis NF & 10,93 & 7,86 & 7,03 & 7,70 & 7,98 & 8,88 & 10 \\
\hline Prazo de entitega & 10,70 & 7,11 & 4,40 & 6,65 & 6,90 & 9,10 & 10 \\
\hline Serviço de entriega & 7,90 & 7,05 & 5,90 & 6,90 & 7,03 & 8,23 & 10 \\
\hline Preceos raticicados & 7,58 & 7,06 & 6,00 & 7,45 & 7,35 & 7,88 & 10 \\
\hline Merchandising & 6,83 & 5,81 & 2,20 & 2,80 & 7,48 & 8,48 & 10 \\
\hline Flex preçopprazo & 6,48 & 6,75 & 3,98 & 4,00 & 7,75 & 8,78 & 10 \\
\hline Prazo pagto & 6,45 & 7,52 & 6,68 & 7,45 & 8,15 & 8,60 & 10 \\
\hline Forma pagto & 6,05 & 7,89 & 7,33 & 7,38 & 7,88 & 8,28 & 10 \\
\hline Acessofácil & 5,33 & 5,93 & 4,15 & 5,30 & 6,43 & 8,15 & 10 \\
\hline Pedidos extras & 4,85 & 7,06 & 4,85 & 6,63 & 7,78 & 8,55 & 10 \\
\hline imite crédito & 4,43 & 8,07 & 7,30 & 7,75 & 8,45 & 8,90 & 10 \\
\hline
\end{tabular}

Fonte: Pesquisa.

A Tabela 8 resume para cada atributo o grau de importância, as práticas médias de mercado - tomadas pelas médias globais de avaliação do desempenho de todos os fornecedores -, as piores e as melhores práticas do mercado, o desempenho das empresas $\boldsymbol{F}$ e $\boldsymbol{I}$, e a máxima pontuação. A comparação dos índices obtidos por uma empresa com os demais resultados é reveladora do seu posicionamento no mercado e serve de base para o replanejamento das políticas e ações focadas no nível de satisfação de seus clientes.

A apuração das lacunas de percepção entre o serviço prestado por uma empresa e as melhores práticas do mercado (benchmark) pode contribuir significativamente para que uma empresa identifique boas oportunidades para o aperfeiçoamento de sua estratégia de serviço. A Figura 3 mostra a comparação dos níveis de serviço percebidos pelos clientes supermercadistas para as empresas $\boldsymbol{F}$ e $\boldsymbol{I}$, com as melhores e piores práticas do mercado e com o serviço médio apurado em cada atributo. Os atributos estão colocados em ordem de importância.

Figura 3 - Gráfico comparativo das percepções do desempenho

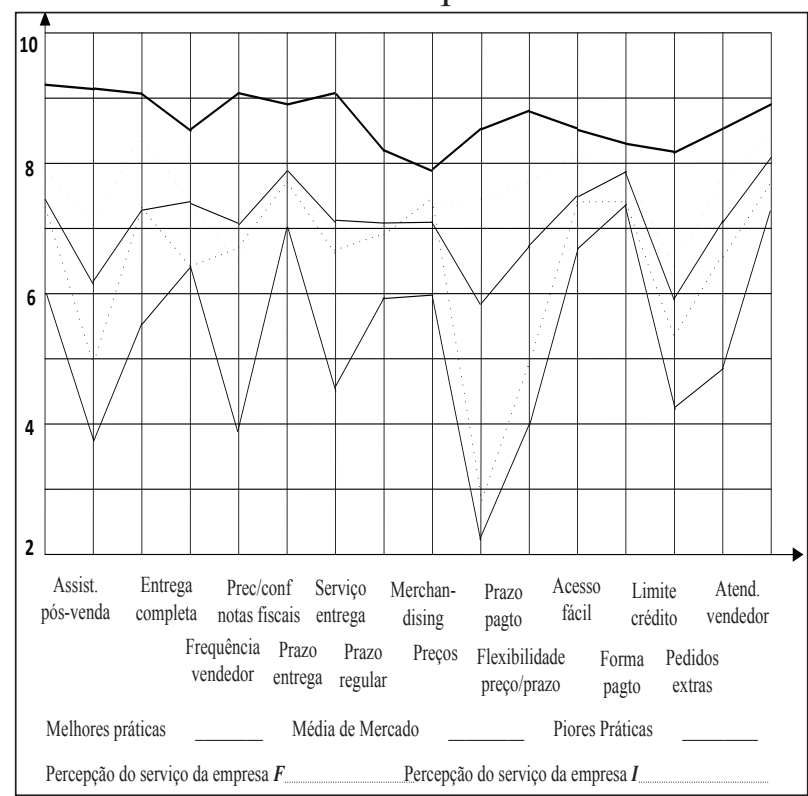

Fonte: Pesquisa.

Uma simples observação do gráfico é suficiente para revelar lacunas importantes entre o desempenho das empresas F e I, sobretudo nos atributos assistência pós-venda, merchandising e flexibilidade em preços e prazos em campanhas promocionais. No quesito entrega completa, a empresa $\mathbf{F}$ tem a pior prática do mercado, chegando a superar ligeiramente a sua principal concorrente em apenas dois quesitos: regularidade do prazo de entrega e preços. Nos demais atributos, a empresa $\mathbf{F}$ tem um desempenho inferior ao da sua concorrente. No cômputo geral, a empresa concorrente tem um desempenho superior ao da empresa $\mathbf{F}$ e da média do mercado. É visível o distanciamento do desempenho das duas distribuidoras em relação às melhores práticas do mercado, para a maioria dos atributos.

\subsection{A Análise da Matriz de Posicionamento}

Stock e Lambert (2001) propõem duas matrizes. A 
Avaliação do serviço de distribuição ao varejo: um estudo empírico no segmento dos médios supermercados

primeira matriz confronta importância e desempenho; é denominada absoluta. Seus resultados sugerem ações sem o conhecimento da situação dos concorrentes. Na segunda, as lacunas em relação ao desempenho dos concorrentes ou das melhores práticas - são confrontadas, vis a vis, com a importância dos atributos; a matriz é relativa. Os atributos são divididos em três grupos de importância e três grupos de desempenho, formando uma matriz com nove possibilidades. As Tabelas 9 e 10 mostram as diretrizes sugeridas pelos autores nas duas matrizes. $\mathrm{Na}$ matriz relativa, de posicionamento, os três grupos de desempenho são substituídos por três grupos de lacunas: maiores lacunas positivas, maiores lacunas negativas e lacunas intermediárias.

Tabela 9 - Ações para matriz absoluta

\begin{tabular}{|c|c|c|c|}
\hline & Baixo Desempenho & Médio Desempenho & Alto Desempenho \\
\hline Alta Importância & Melhorar s d durida & Melhorar & Melhorarl manter \\
\hline Média Impotância & Melhorar & Manter & Manterl reduzir \\
\hline Baixa Impotanncia & Manter & Manter/ /reduzir & Manterl/ reduzir \\
\hline
\end{tabular}

Fonte: Adaptada de Stock e Lambert (2001)

Tabela 10 - Posicionamento para matriz relativa

\begin{tabular}{|c|c|c|}
\hline & Maiores lacunas nevativas Lacunas intermedidarias & Maiones lacunas posititias \\
\hline & Desvantagem competitiva Paridade competitiva & Vantagem com \\
\hline & Desvantagem competitiva Paridade competitiva & Vantagem competitiva \\
\hline & Desvantagem competitiva Paridade comnetitiva & \\
\hline
\end{tabular}

Fonte: Adaptada de Stock e Lambert (2001).

A Figura 4 mostra a posição relativa de cada empresa, crescente da esquerda para a direita, em cada atributo, segundo a avaliação dos supermercadistas. Os atributos estão ordenados em grau de importância, decrescentemente, de cima para baixo. Observe-se que a empresa $\mathrm{E}$ foi avaliada em todos os atributos como benchmark do mercado. É possível identificar as posições das empresas $\mathrm{F}$ e I em relação a todas as empresas pesquisadas.
Figura 4 - Posicionamento geral das empresas

\begin{tabular}{|c|c|c|c|c|c|c|c|c|c|c|c|c|}
\hline \multirow{3}{*}{\begin{tabular}{|c|} 
Atributos em \\
Ordem de Importância \\
Atendimento do vendedor
\end{tabular}} & & & \multicolumn{10}{|c|}{ Desempenho Relativo } \\
\hline & & & \multicolumn{3}{|c|}{ mais baixo } & \multicolumn{4}{|c|}{ médio } & \multicolumn{3}{|c|}{ mais alto } \\
\hline & & & A & $\mathrm{B}$ & $\mathrm{D}$ & $\mathrm{H}$ & $F$ & $\mathrm{G}$ & $\mathrm{J}$ & $I$ & $\mathrm{C}$ & E \\
\hline Assistência pós-venda & & $\cong$ & A & $F$ & B & D & $\mathrm{C}$ & $\mathrm{H}$ & G & I & $J$ & $\mathrm{E}$ \\
\hline Freq. de passag. vendedor & & & B & A & D & $\mathrm{J}$ & $\mathrm{H}$ & $F$ & G & $\mathrm{C}$ & $I$ & E \\
\hline Entrega completa & & ق & $F$ & A & D & B & $\mathrm{H}$ & I & G & $\mathrm{C}$ & $\mathrm{J}$ & $\mathrm{E}$ \\
\hline Prazo regular & & & A & $I$ & $F$ & $\mathrm{D}$ & $\mathrm{B}$ & $\mathrm{H}$ & $\mathrm{G}$ & $\mathrm{J}$ & $\mathrm{C}$ & E \\
\hline Confiab/precisão N Fiscais & $\underline{2}$ & & A & B & $\mathrm{H}$ & D & $F$ & G & $I$ & $\mathrm{C}$ & $\mathrm{J}$ & E \\
\hline Prazo de entrega & . & & A & B & D & $F$ & I & $\mathrm{H}$ & G & C & $\mathrm{J}$ & E \\
\hline Serviço de entrega & & 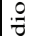 & A & B & $F$ & $\mathrm{H}$ & I & D & G & $\mathrm{J}$ & $\mathrm{C}$ & E \\
\hline Preços praticados & & & A & B & $\mathrm{D}$ & $\mathrm{C}$ & $\mathrm{H}$ & $I$ & $F$ & G & $\mathrm{J}$ & $\mathrm{E}$ \\
\hline Merchandising & & & A & B & $F$ & D & $\mathrm{H}$ & I & $\mathrm{C}$ & $\mathrm{G}$ & $\mathrm{J}$ & E \\
\hline Flexibilidade preço/prazo & $\tau$ & & A & B & $F$ & D & $\mathrm{C}$ & G & $\mathrm{H}$ & I & $\mathrm{J}$ & E \\
\hline Prazo de pagamento & & & $\mathrm{C}$ & B & D & A & $\mathrm{H}$ & $F$ & $\mathrm{G}$ & $I$ & $\mathrm{~J}$ & E \\
\hline Forma de pagamento & & & B & $F$ & $\mathrm{H}$ & $I$ & A & D & G & $\mathrm{J}$ & C & $\mathrm{E}$ \\
\hline Acesso fácil e direto & & & A & $\mathrm{B}$ & $F$ & $\mathrm{D}$ & $\mathrm{H}$ & $\mathrm{J}$ & $\mathrm{G}$ & $I$ & C & E \\
\hline Pedidos extras & & 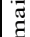 & A & $\mathrm{B}$ & $F$ & $\mathrm{D}$ & $\mathrm{G}$ & $\mathrm{H}$ & $\mathrm{J}$ & $I$ & $\mathrm{C}$ & E \\
\hline Limite crédito & & & D & B & $F$ & A & $\mathrm{G}$ & $\mathrm{H}$ & $\mathrm{J}$ & $I$ & C & $\mathrm{E}$ \\
\hline
\end{tabular}

Fonte: Pesquisa.

A Figura 5 mostra a posição da empresa foco $(\boldsymbol{F})$ e de sua principal concorrente $(I)$ sem considerar a posição relativa das demais empresas. Cada faixa de desempenho é contemplada com um terço da escala absoluta de avaliação. A configuração da matriz absoluta da Figura 5 sugere que a empresa $\boldsymbol{F}$ deveria melhorar duas posições dentre os atributos mais importantes, independentemente do posicionamento de seu concorrente mais direto: assistência pós-venda e entrega completa. As duas variáveis são de natureza logística. Nesse grupo há um único atributo, regularidade do prazo de entrega, para o qual a posição de $\boldsymbol{F}$ é ligeiramente superior à de sua concorrente direta. No atributo merchandising, grupo intermediário, constata-se uma lacuna significativa entre os concorrentes e uma indicação clara para melhorar o desempenho da empresa $\boldsymbol{F}$. Nesse grupo e no grupo de atributos de menor importância, o desempenho da concorrente é notavelmente superior. 
Figura 5 - Desempenho das empresas F e I

\begin{tabular}{|c|c|c|c|c|c|c|}
\hline Atributos & melhorar s/ dúvida & \multicolumn{2}{|c|}{ melhorar } & melhorar/manter & $\mathrm{F}$ & I \\
\hline Atend. vendedor & & & & क斥家 & 7,38 & 7,95 \\
\hline Assist. pós-venda & & $\mid \hat{y}$ & & 0 & 3,93 & 7,05 \\
\hline Passag. vendedor & & & & 约 & 7,33 & 8,40 \\
\hline Entrega completa & & & 构 & 0 & 6,38 & 7,43 \\
\hline \multirow[t]{2}{*}{ Prazo regular } & & & a & & 6,73 & 6,50 \\
\hline & melhorar & \multicolumn{2}{|l|}{ manter } & manter/reduzir & & \\
\hline Confiab/prec NF & & & & 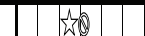 & 7,70 & 7,98 \\
\hline Prazo de entrega & & & & 8) & 6,65 & 6,90 \\
\hline Serviço de entrega & & & & 绳 & 6,90 & 7,03 \\
\hline Preços praticados & & & & 这 & 7,45 & 7,35 \\
\hline Merchandising & & & & 8 & 2,80 & 7,48 \\
\hline \multirow[t]{2}{*}{ Flex. preço/prazo } & & 放 & & (8) & 4,90 & 7,75 \\
\hline & manter & \multicolumn{2}{|c|}{ manter/reduzir } & manter/reduzir & & \\
\hline Prazo pagto & & & & 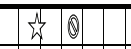 & 7,45 & 8,15 \\
\hline Forma pagto & & & & 纷更 & 7,38 & 7,88 \\
\hline Acesso fácil & & 紊 & 0 & 41 & 5,30 & 6,43 \\
\hline Pedidos extras & & & 5 & (a) & 6,63 & 7,78 \\
\hline Limite crédito & & & & 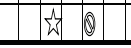 & 7,75 & 8,45 \\
\hline$F(\hbar)$ & & & 6, & & 10 & $I(\mathbb{8})$ \\
\hline
\end{tabular}

Para uma análise mais precisa e uma aplicação mais ajustada da matriz relativa, é necessário comparar o desempenho da empresa foco $\boldsymbol{F}$ com o benchmark e com a empresa concorrente que assume um embate mais direto no mercado. O benchmark é o conjunto dos melhores resultados em cada atributo, não sendo necessariamente representado pelos resultados de uma única empresa. Nesta pesquisa, a empresa $\boldsymbol{E}$ alcançou os melhores resultados em todos atributos. Já a comparação com o principal concorrente é realizada com os resultados alcançados no conjunto de atributos de uma mesma empresa, no caso, a distribuidora $\boldsymbol{I}$. A Figura 6 revela a comparação do desempenho das duas empresas com as melhores práticas do mercado, ao mesmo tempo que reflete a comparação direta entre $\boldsymbol{F}$ e $\boldsymbol{I}$.

Um valor negativo indica um desempenho inferior à base de comparação. Há um significado muito diferente entre as duas comparações. A primeira comparação ode indicar movimentos para superar um concorrente direto sem levar em consideração as melhore práticas. A empresa $\mathrm{F}$ poderia obter uma vantagem competitiva em relação ao seu concorrente mais direto, sem, no entanto, considerar práticas adequadas de um processo de benchmarking. Em situações como essa, a vantagem competitiva alcançada poderia diluir-se rapidamente, pois as melhores práticas estariam sendo negligenciadas.
Figura 6 - Desempenho das empresas F e I em relação às melhores práticas

\begin{tabular}{|c|c|c|c|c|c|c|}
\hline \multirow{2}{*}{ Atributos } & \multicolumn{2}{|c|}{ Desvantagem } & Paridade & Vantagem & \multicolumn{2}{|c|}{ Lacunas } \\
\hline & \multicolumn{2}{|c|}{ melhorar s/ dúvida } & melhorar & melhorar/manter & $F$ & $\mathrm{H}$ \\
\hline Atend. vendedor & & & $\begin{array}{ll}4 \\
\end{array}$ & & $-1,83$ & $-1,25$ \\
\hline Assist. pós-venda & 式 & 0 & a & & $-5,20$ & $-2,08$ \\
\hline Passag, vendedor & & & 同 & & $-1,73$ & $-0,65$ \\
\hline Entrega completa & & 5 & a & & $-2,08$ & $-1,03$ \\
\hline \multirow[t]{2}{*}{ Prazo regular } & & Oर & & & $-2,43$ & $-2,65$ \\
\hline & \multicolumn{2}{|c|}{ melhorar } & manter & manter/reduzir & & \\
\hline Confiab/prec NF & & & the & & $-1,18$ & $-0,90$ \\
\hline Prazo de entrega & & 40 & & & $-2,45$ & $-2,20$ \\
\hline Serviço de entrega & & & 68 & & $-1,33$ & $-1,20$ \\
\hline Preços praticados & & & 极 & & $-0,43$ & $-0,53$ \\
\hline Merchandising & 勾 & & 0 & & $-5,68$ & $-1,00$ \\
\hline \multirow[t]{2}{*}{ Flex. preço/prazo } & & & 0 & & $-3,88$ & $-1,03$ \\
\hline & \multicolumn{2}{|c|}{ manter } & manter/reduzir & manter/reduzir & & \\
\hline Prazo pagto & & & 站 & & $-1,15$ & $-0,45$ \\
\hline Forma pagto & & & 故 & & $-0,90$ & $-0,40$ \\
\hline Acesso fácil & & th & (a) & & $-2,85$ & $-1,73$ \\
\hline Pedidos extras & & & $\begin{array}{lll}7 & 0\end{array}$ & & $-1,93$ & $-0,78$ \\
\hline Limite crédito & & & 氛 & & $-1,15$ & $-0,45$ \\
\hline$F($ 负 $)$ & $-6 \quad-5$ & -3 & $-2-1$ & 4 & 6 & $I(\theta)$ \\
\hline
\end{tabular}

Fonte: pesquisa.

A análise da configuração final da matriz relativa de desempenho da empresa F, considerando o grau de importância dos atributos - aqui agrupados em alta, média e baixa importância -, refletindo a ordem de grandeza das lacunas de desempenho (gaps) em relação às melhores práticas e observando a posição relativa do seu concorrente mais direto, sugere que:

- $\quad$ A empresa $\boldsymbol{F}$ precisa melhorar seu desempenho em todos os atributos do grupo de alta importância, e, sem dúvida, os serviços de assistência pós-venda, entrega completa e regularidade do prazo de entrega, para os quais se posiciona em desvantagem competitiva na relação com as melhores práticas. Nesse grupo, a empresa concorrente mais direta apresenta superioridade em quatro dos cinco atributos, à exceção de regularidade no prazo de entrega, ainda assim com diferença não significativa.

- No grupo de média importância, a empresa $\boldsymbol{F}$ precisa melhorar $50 \%$ dos atributos para os quais se encontra em desvantagem competitiva: prazo de entrega, merchandising e flexibilidade de preços e prazos em campanhas promocionais. $\mathrm{O}$ concorrente mais direto tem acentuada vantagem no desempenho dos atributos merchandising e flexibilidade de preços e prazos. 
Avaliação do serviço de distribuição ao varejo: um estudo empírico no segmento dos médios supermercados

- Para o grupo de baixa importância, quase todos os atributos de $\boldsymbol{F}$ estão em paridade competitiva com as melhores práticas; a exceção fica por conta do acesso fácil e direto dos clientes. Em todos os atributos, o concorrente mais direto mantém um desempenho melhor, sendo mais acentuado no acesso fácil e direto e no atendimento de pedidos extras.

A matriz relativa de desempenho e o quadro geral de posicionamento apresentado na Figura 4 indicam claramente que a empresa $\boldsymbol{F}$, segundo a percepção dos clientes, não tem uma posição confortável diante dos seus concorrentes. A matriz oferece uma visão clara do posicionamento de cada empresa no mercado. Dela, podem ser extraídas informações importantes para o desdobramento das ações a serem empreendidas. Uma auditoria interna na empresa $\boldsymbol{F}$ ajudaria a complementar o quadro de informações necessárias ao estabelecimento de uma estratégia competitiva que pudesse alterar o atual posicionamento.

\section{CONSIDERAÇÕES FINAIS}

As informações obtidas sobre a distribuição física, as preferências prospectadas, a importância aferida e as percepções levantadas sobre as dimensões do serviço ao cliente constituem um material relevante para um estudo continuado da distribuição logística. Os resultados respondem às questões importantes colocadas no escopo deste artigo. Sugerem que tanto atributos do serviço do marketing quanto atributos do serviço logístico são determinantes para o nível de satisfação ao cliente e que as dimensões logísticas assumem um grau maior de importância quando postos lado a lado.

Os supermercadistas avaliaram todos os atributos como muito importantes. No entanto, quando foram demandados a realizar uma hierarquização, puderamse constatar suas expectativas em relação à importância relativa de cada um. No grupo dos mais importantes, prevaleceu a presença de atributos logísticos, mesmo considerando a presença, no conjunto geral de atributos, de variáveis de natureza eminentemente mercadológicas como preços praticados, prazo e formas de pagamento, merchandising e flexibilidade de preços e prazos em campanhas promocionais

Com os resultados da avaliação dos fornecedores pelos supermercadistas, foi possível atender ao objetivo específico de conhecer a qualidade do serviço oferecido sob a percepção dos clientes em cada uma de suas dimensões - e estabelecer o benchmark do mercado, as piores práticas e a prática média corrente.

Compreender e identificar os atributos que os varejistas percebem como mais importantes, ajudam aos gestores a focar o aperfeiçoamento dos níveis de serviço desses atributos e a trabalhar para manter níveis de serviço aceitáveis em atributos menos importantes, enquanto reduz o custo global do fornecimento do serviço. Com a aplicação das matrizes de importância x desempenho é possível compreender como os fornecedores se posicionam estrategicamente no mercado em relação ao serviço oferecido.

Os resultados revelam, ademais, que há um largo campo - provavelmente pouco explorado de forma racional para que os distribuidores possam trabalhar as lacunas de serviço percebidas pelos supermercadistas, atributo a atributo, no serviço de distribuição. Os indicadores confluem para um conjunto de oportunidades que pode dar suporte a processos de reformulação e aperfeiçoamento das suas políticas de serviço aos clientes.

\section{REFERÊNCIAS}

ABAD, Ranking 2005. Revista Distribuição, v. 13, n. 147, p. 70-173, São Paulo, 2005.

BAKI, Birdogan; BASFIRINCI, Cigdem; CILINGIR, Zuhal; MURAT, Ilker. An application of integrating SERVQUAL and Kano's model into QFD for logistics services: A case study from Turkey. Asia Pacific Journal of Marketing and Logistics, v. 21, n. 1, p. 106-126, 2009.

BANOMYONG, Ruth; SUPATN, Nucharee. Selecting logistics providers in Thailand: a shippers' perspective. European Journal of Marketing, v. 45, n. 3, p. 419-437, 2011. 
BOURLAKIS, Michael; MELEWAR, T.C. Marketing perspectives of logistics service providers: present and future research directions. European Journal of Marketing, v. 45, n. 3, p. 300-310, 2011.

BOWERSOX, D. J.; CLOSS D. J. Logística empresarial, São Paulo: Atlas, 2001.

BOWERSOX, D. J; ClOSS D. J.; COOPER, M. B. Gestão logística de cadeias de suprimentos, Porto Alegre: Bookman, 2006.

CAMPOS, Domingos F., Como os gestores avaliam as necessidades de seus clientes? Um estudo comparativo das percepções de clientes e fornecedores no pequeno varejo alimentar, in: Varejo competitivo, v. 12, p. 85111, São Paulo: Saint Paul Editora, 2007.

CAMPOS, Domingos F., A importância do nível de serviço e o impacto das grandes cadeias de auto-serviço no abastecimento do pequeno varejo alimentar. Revista Econômica do Nordeste, v. 38, n. 3, p. 486-501, Fortaleza, 2007.

CHRISTOPHER, Martin, Logística e gerenciamento da cadeia de suprimentos. São Paulo: Pioneira, 1997.

COOPER, D.; SCHINDLER, P. Métodos de Pesquisa em Administração. São Paulo: Bookman, 2003.

ELLRAM, L. M.; LA LONDE, B. J.; WEBER, M. M. Retail logistics. International Journal of Physical Distribution and Logistics Management, v. 29, n. 7/8, p. 477-494, 1999.

FLEURY, Paulo F.; LAVALLE, C.; Avaliação do serviço de distribuição física: a relação entre a indústria de bens de consumo e o comércio atacadista e varejista. Revista Tecnologística, mai/jun, 1997.

FLUD, Paula B., Necessidade e uso de informação para negócios pelos gestores do setor supermercadista de Campo Grande/MS, Dissertação de Mestrado, Universidade de Brasília, Brasília, 2006.

GRIFFIS, S. E.; COOPER, M.; GOLDSBY, T. J.; CLOSS, D. J., Performance measurement: measure selection based upon firm goals and information reporting needs. Journal of Business Logistics, v. 25, n. 2, p. 95-118, 2004.

GRÖNROOS, Christian, Um modelo de qualidade de serviço e suas implicações para o marketing. Revista de Administração de Empresas, v. 46, n. 4, p. 88-95, 2006.

HIJJAR, Maria F., Diagnóstico externo do sistema logístico: utilizando pesquisas de serviço do cliente para identificação de oportunidades de melhorias. Revista Tecnologística, vol. 6, n. 70, p. 60-66, 2001.

INNIS, D. E.; LA LONDE, B. J., Customer service: the key to customer satisfaction, customer loyalty, and market share. Journal of Business Logistics, v. 15, n. 1, p. 1-28, 1994.

JUGA, Jari; JUNTUNEN, Jouni; GRANT, David. Service quality and its relation to satisfaction and loyalty in logistics outsourcing relationships. Managing Service Quality, v. 20, n. 6, p. 496-510, 2010.

KERSTEN, Wolfgang; KOCH, Jan. The effect of quality management on the service quality and business success of logistics service providers. International Journal of Quality \& Reliability Management, v. 27, n. 2, p. 185200, 2010.

LA LONDE, B. J.; COOPER, M.C.; NOORDEWIER, T.G., Customer service: a management perspective. Council of Logistics Management, Oak Brook, IL, 1988.

LA LONDE, B. J., ZINSZER, P. H., Customer service: meaning and measurement (Chicago: National Council of Physical Distribution Management), 1976.

LAVALlE, C.; FIGUEIREDO, K.; HIJJAR, M. F.; ARKADER, R., Evolução do desempenho logístico das indústrias de bens de consumo: uma análise sob a perspectiva do varejista. Revista Tecnologística, vol. 8, n. 93, p. 72-79, 2003.

LAVALlE, C., Pesquisa Benchmark 2007 - Serviço de Distribuição Física. Revista Tecnologística, vol. 13, n. 142, p. 96-103, 2007. 
Avaliação do serviço de distribuição ao varejo: um estudo empírico no segmento dos médios supermercados

MAIA, Leonardo C. C., Avaliação do serviço logístico sob a percepção do varejo: um estudo empírico numa rede voluntária de supermercados patrocinada pelo atacado. Dissertação de Mestrado, Universidade Federal de Uberlândia, Uberlândia, 2006.

MARR, N. E. Do managers really know what service their customers require? International Journal of Physical Distribution \& Logistics Management, v. 24, n. 4, p. 24-31, 1994.

MENTZER, J. T.; FLINT, D. J. G.; HULT, T. M., Logistics service quality as a segment-customized process. Journal of Marketing, v. 65, n. 4, p. 82-104, 2001.

MENTZER, J. T.; DEWITT, W.; KEEBLER, J. S.; et al. Defining supply chain management. Journal of Business Logistics, v. 22, n. 2, p. 1-25, 2001.

MENTZER, J. T.; GOMES, R.; KRAPFEL, R., Physical distribution device: a fundamental marketing concept. Journal of the Academy of Marketing Science, v. 17, n. 1, p. 53-62, 1989.

PARASURAMAN, A.; ZEITHAML, V; BERRY, L. Delivering quality service: balancing customer perceptions and expectations. New York: The Free Press, 1990.

REVISTA SUPERMERCADO MODERNO, Censo NIELSEN 2007, Disponível em: http://www.sm.com.br/ mediakit/cobert2.htm\#1, Acesso em: 25 fev. 2008.

SAURA, Irene; FRANCES, David; CONTRI, Gloria; BLASCO, Marı. Logistics service quality: a new way to loyalty. Industrial Management \& Data Systems, v. 108, n. 5, p. 650-668, 2008.

STANK, T. P.; DAUGHERTY, P. J.; ELLINGER, A. E. Voice of the customer: the impact on customer satisfaction. International Journal of Purchasing and Materials Management, v. 33, n. 4, p. 2-9, 1997.

STOCK, J. R.; LAMBERT, D. M. Strategic logistics management., New York: McGraw Hill, 2001. 